\title{
Stable Lithium-Carbon Composite Enabled by Dual-Salt Additives
}

Cite as

Nano-Micro Lett.

(2021) 13:111

Received: 9 December 2020

Lei Zheng ${ }^{1,2}$, Feng Guo ${ }^{1,2}$, Tuo Kang ${ }^{2}$, Yingzhu Fan ${ }^{2}$, Wei Gu ${ }^{2}$, Yayun $\mathrm{Mao}^{2}, \mathrm{Ya} \mathrm{Liu}^{2}$,

Accepted: 25 February 2021

Rong Huang ${ }^{3}$, Zhiyun $\mathrm{Li}^{3}$, Yanbin Shen ${ }^{2}{ }^{凶}$, Wei Lu², Liwei Chen ${ }^{2,4}$

Published online: 17 April 2021

(C) The Author(s) 2021

\section{HIGHLIGHTS}

- It is the first report that using dual-salt additives of $\mathrm{LiPF}_{6}$ and $\mathrm{LiNO}_{3}$ to significantly improve the cycling performance of the $\mathrm{Li}-\mathrm{CNT}$ negative electrode.

- The mechanism why the combined use of $\mathrm{LiPF}_{6}$ and $\mathrm{LiNO}_{3}$ additive can improve the cycling performance and rate capability of the Li-CNT negative electrode was investigated.

- An average cycling Coulombic efficiency as high as $99.30 \%$ was obtained for the Li-CNT negative electrode at a current density of $2.5 \mathrm{~mA} \mathrm{~cm}^{-2}$ and an negative electrode to positive electrode capacity (N/P) ratio of 2 .

ABSTRACT Lithium metal is regarded as the ultimate negative electrode material for secondary batteries due to its high energy density. However, it suffers from poor cycling stability because of its high reactivity with liquid electrolytes. Therefore, continuous efforts have been put into improving the cycling Coulombic efficiency (CE) to extend the lifespan of the lithium metal negative electrode. Herein, we report that using dual-salt additives of $\mathrm{LiPF}_{6}$ and $\mathrm{LiNO}_{3}$ in an ether solvent-based electrolyte can significantly improve the cycling stability and rate capability of a Li-carbon (Li-CNT) composite. As a result, an average cycling $\mathrm{CE}$ as high as $99.30 \%$ was obtained for the Li-CNT at a current density of $2.5 \mathrm{~mA} \mathrm{~cm}^{-2}$ and an negative electrode to positive electrode capacity $(\mathrm{N} / \mathrm{P})$ ratio of 2 . The cycling stability and rate capability enhancement of the Li-CNT negative electrode could be attributed to the formation of

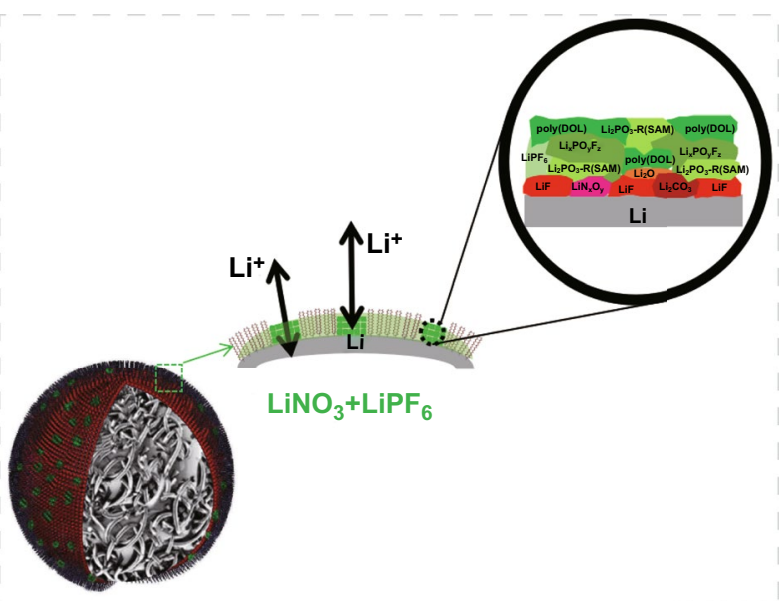
a better solid electrolyte interphase layer that contains both inorganic components and organic polyether. The former component mainly originates from the decomposition of the $\mathrm{LiNO}_{3}$ additive, while the latter comes from the $\mathrm{LiPF}$-induced ring-opening polymerization of the ether solvent. This novel surface chemistry significantly improves the CE of Li negative electrode, revealing its importance for the practical application of lithium metal batteries.

Yanbin Shen, ybshen2017@sinano.ac.cn

School of Nano-Tech and Nano-Bionics, University of Science and Technology of China, Hefei 230026, People's Republic of China

2 i-Lab, CAS Center for Excellence in Nanoscience, Suzhou Institute of Nano-Tech and Nano-Bionics, Chinese Academy of Science, Suzhou 215123, People's Republic of China

3 Vacuum Interconnected Nanotech Workstation (Nano-X), Suzhou Institute of Nano-Tech and Nano-Bionics (SINANO), Chinese Academy of Science (CAS), Suzhou 215123, People's Republic of China

4 in-Situ Center for Physical Science, School of Chemistry and Chemical Engineering, Shanghai Jiaotong University, Shanghai 200240, People's Republic of China 
KEYWORDS Lithium metal battery; Coulombic efficiency; Dual-salt additives; Li-CNT; Solid electrolyte interphase

\section{Introduction}

Lithium (Li) has been regarded as the ultimate negative electrode material for high energy density secondary batteries owing to its high energy density [1-7]. However, Li metal is highly reactive to electrolytes and is prone to the dendrite formation during the Li striping/plating cycling, resulting in limited cycle life and severe safety issue that largely impede the practical application of lithium metal batteries [5, 8-12]. Tremendous efforts have been dedicated to addressing the above problems in the last few decades, mainly including (1) regulating the homogeneity of $\mathrm{Li}$ deposition through controlling the negative electrode surface chemistry to suppress the dendrite formation [13-17], (2) employing 2D/3D hosts for the Li metal to increase the specific surface area of the negative electrode thus decrease the current density to suppress the dendrite formation [18-21], and (3) solidify the electrolyte or constructing a solid layer on Li surface to protect it from reacting with electrolytes [22-29].

Although many improvements in Li stability have been reported, typical average cycling Coulombic efficiency (CE) of Li metal in a commercial carbonate or ether solvent-based electrolyte at a practical current density $\left(>3 \mathrm{~mA} \mathrm{~cm}^{-2}\right)$ is usually lower than $99.0 \%$ [30-35] (Table S1), which is far below the standard required for practical application. The lifespan of a lithium metal negative electrode is critically dependent on its CE (Fig. 1). Suppose that the end of life capacity retention is $80 \%$, a lithium metal with an average cycling CE of $99.926 \%$ can sustain 300 cycles of Li plating/ stripping, but the one with an average cycling CE of $99.0 \%$ can only sustain a lifespan less than 30 cycles. As a result, a large excess of lithium metal (negative electrode to positive electrode capacity $(\mathrm{N} / \mathrm{P})$ ratio $>50)$ is required to artificially enhance the cycle life, which brings down the volumetric energy density of the cell. Therefore, despite all the challenges, it is still crucial and worthwhile to push on the effort in improving the average cycling CE of lithium metal.

Recently, we reported a lithium-carbon nanotube (LiCNT) microsphere composite with a hydrophobic selfassembled monolayer (SAM) surface passivation layer as an negative electrode material [36-42]. With the protection of the SAM layer, the Li-CNT composite exhibited an average cycling CE beyond $99.0 \%$ at a small N/P ratio of 2 [41]. However, the SAM layer could be damaged during Li plating/stripping cycles, which limited further improvement of CE [42].

In this work, we demonstrated the combined use of two additives, i.e., $\mathrm{LiPF}_{6}$ and $\mathrm{LiNO}_{3}$, in an ether-based electrolyte can generate a thin but robust solid electrolyte interphase (SEI) layer on Li-CNT when the SAM passivation layer was damaged, significantly improve the cycling stability and rate capability of the Li-CNT negative electrode. As a result, an average cycling CE as high as $99.30 \%$ was obtained for the Li-CNT composite negative electrode at a current density of $2.5 \mathrm{~mA} \mathrm{~cm} \mathrm{~cm}^{-2}$ and an N/P of 2.

\section{Experimental}

\subsection{Material Synthesis and Li-CNT Electrode Preparation}

The Li-CNT composite was synthesis according to our previous reports [37, 39-43]. $2 \mathrm{~g}$ of porous carbon nanotubes microspheres prepared by spray-drying were mixed with $4 \mathrm{~g}$ of $\mathrm{Li}$ in an Ar-filled glovebox at $180{ }^{\circ} \mathrm{C}$ for $20 \mathrm{~min}$ under stirring of $500 \mathrm{r} \mathrm{min}^{-1}$ [37, 41]. For the SAM passivation, $1 \mathrm{~g}$ of the Li-CNT was added to $10 \mathrm{~mL}$ of tetrahydrofuran (THF) solution containing 0.1 wt.\%

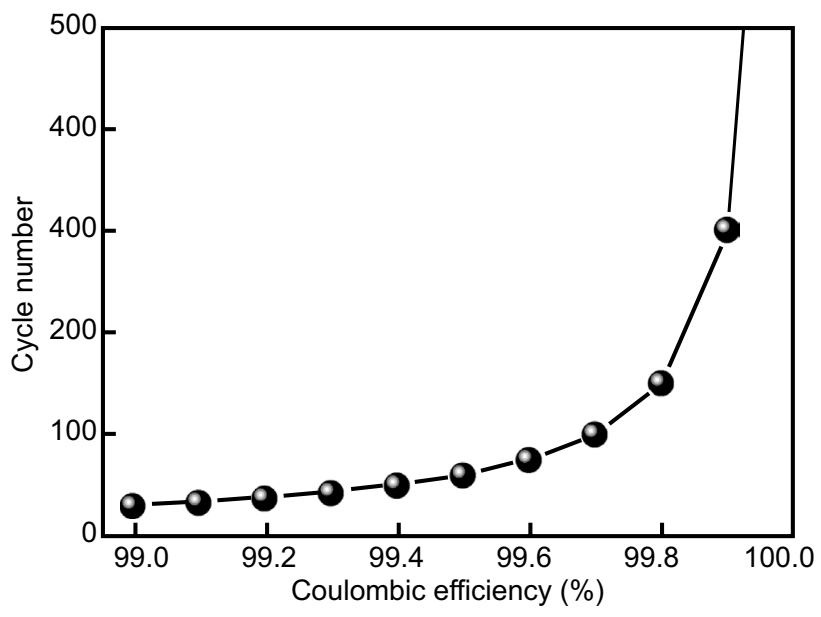

Fig. 1 Calculated lifespan of a lithium metal anode based on its CE 
dihexadecanoalkyl phosphate (DHP) under stirring for $30 \mathrm{~min}$. The resulting solution was vacuum-dried overnight to obtain the Li-CNT composite. To prepare a Li-CNT negative electrode, $20 \mathrm{mg}$ of poly(styrene-co-butadiene) (Sigma-Aldrich), $20 \mathrm{mg}$ of polystyrene (molecular weight: 2,000,000, Alfa Aesar), $40 \mathrm{mg}$ of acetylene black, and $320 \mathrm{mg}$ of Li-CNT composite were dissolved in a $1.5 \mathrm{~mL}$ p-xylene solvent (anhydrous, 99.5\%, Sigma-Aldrich), and magnetically stirred for $4 \mathrm{~h}$, then the slurry was coated on a copper foil, followed by vacuum-drying at $60{ }^{\circ} \mathrm{C}$ for $8 \mathrm{~h}$ in an Ar-filled glove box $\left(\mathrm{O}_{2}<0.01 \mathrm{PPM}, \mathrm{H}_{2} \mathrm{O}<0.01\right.$ PPM) $[37,41]$. The areal capacity loading of the Li-CNT electrode can be controlled by varying the thickness of the electrode. In this work, the areal capacity loading of the LiCNT electrode used in the Li-CNTILi-CNT symmetric cell is $10 \mathrm{~mA} \mathrm{~h} \mathrm{~cm}{ }^{-2}$. While in the Li-CNT\|LFP cell, in order to obtain a low N/P ratio of 2 , the areal capacity loading of the $\mathrm{Li}-\mathrm{CNT}$ electrode is controlled to be $5 \mathrm{mAh} \mathrm{cm}^{-2}$. The deep-depth of discharge for the Li-CNT\|Li-CNT symmetric cell and the $\mathrm{Li}-\mathrm{CNT} \| \mathrm{LiFePO}_{4}$ full battery is $30 \%$ and $50 \%$, respectively. All the Li-CNTILFP cell was charging and discharging between 2.5-4.1 V.

\subsection{Physical and Chemical Characterizations}

The morphology of the sample was characterized by scanning electron microscopy (SEM, Hitachi Regulus 8230) at $5 \mathrm{kV}$. Elemental composition was analyzed by energy-dispersive X-ray spectroscopy (EDS, Quanta FEG 250) operated at $20 \mathrm{kV}$. The X-ray photoelectron spectroscopy (XPS, PHI-5000 VersaProbe) of sample measurements all employed $\mathrm{Al} \mathrm{K} \alpha$ radiation. The vibrational spectrum of SAM was characterized by sum-frequency generation (SFG) spectroscopy using an EKSPLA system with a copropagating configuration. The time-of-flight secondary ion mass spectrometry (TOF.SIMS5-100) was equipped with a $10 \mathrm{kV} \mathrm{Bi}^{+}$ions analysis beam and $1 \mathrm{kV} \mathrm{Cs}^{+}$sputtering for detecting negative secondary-ion fragments. The dimethyl carbonate was applied as a cleaning agent for cycled electrodes before the characterization.

\subsection{Electrochemical Characterizations}

The 2025 button-type cells were assembled using Li-CNT as the negative electrode, polypropylene membrane (Celgard
2400) as the separator, lithium iron phosphate (LFP, Sinlion Battery Tech, Co., Ltd.) with an area capacity of $2.5 \mathrm{mAh} \mathrm{cm}^{-2}$ was used as the positive electrode, $1.0 \mathrm{M}$ LiTFSI dissolved in a mixed solvent of DOL and DME (1:1 in volume) with $2 \mathrm{wt} . \% \mathrm{LiNO}_{3}$ (Sigma-Aldrich) as the baseline electrolyte. The amount of electrolyte used was estimated at $60 \mu \mathrm{L}$ for each cell. The battery charger system from NEWARE Technology Ltd., Shenzhen was used for the charging/discharging test. The electrochemical impedance spectroscopy was obtained on a VMP300 electrochemical workstation (Bio-Logic, France) in a frequency range from 100 to $1 \mathrm{MHz}$ with an amplitude of $10 \mathrm{mV}$. Five parallel cells were used for each test.

\section{Results and Discussion}

The Li-CNT composite was prepared by impregnating spray-dried CNT microparticles with molten Li to obtain a Li-CNT composite, which was subsequently passivated by a hydrophobic SAM layer of dihexadecanoalkyl phosphate (DHP) via a simple wet chemistry method [41, 42]. The SAM passivated Li-CNT composite has a micro-spherical shape with a diameter of about $5 \mu \mathrm{m}$ (Fig. S1a). The successful preparation of the DHP SAM layer was verified by EDS, XPS, and SFG characterization (Fig. S1b-g). The SAM passivated Li-CNT composite shows a specific capacity of $1912 \mathrm{mAh} \mathrm{g}^{-1}$ at room temperature under a current density of $0.25 \mathrm{~mA} \mathrm{~cm}^{-2}$, and limited capacity loss $\left(150 \mathrm{mAh} \mathrm{g}^{-1}\right)$ was measured after storing in dry air (dew point: $-40^{\circ} \mathrm{C}$ ) for a week (Fig. S1h).

Li stripping/plating behaviors of SAM passivated Li-CNT (areal capacity loading: $10 \mathrm{mAh} \mathrm{cm}^{-2}$ ) symmetric cells with two different electrolytes are shown in Fig. 2. When using a typical ether-based electrolyte, that is, $1.0 \mathrm{M}$ LiTFSI in a mixed solvent of DOL and DME (1:1 in volume), with 2 wt. $\% \mathrm{LiNO}_{3}$ additive, the Li-CNTILi-CNT cell shows stable Li stripping/plating for only $\sim 60$ cycles at a current density of $3 \mathrm{~mA} \mathrm{~cm}^{-2}$ and $3 \mathrm{mAh} \mathrm{cm}^{-2}$, and the overpotential quickly ascends, reaching $260 \mathrm{mV}$ at the 250th cycle (Fig. 2a, red color). The overpotential of the Li-CNT\|LiCNT cell with a single $\mathrm{LiPF}_{6}$ additive is even larger than that with $\mathrm{LiNO}_{3}$ additive and also quickly ascends after $\sim 50$ cycles (Fig. 2a, orange color). In sharp contrast, the LiCNTIILi-CNT symmetric cell with a dual-salt additives of $\mathrm{LiPF}_{6}$ and $\mathrm{LiNO}_{3}$ cycled at the same condition exhibits 

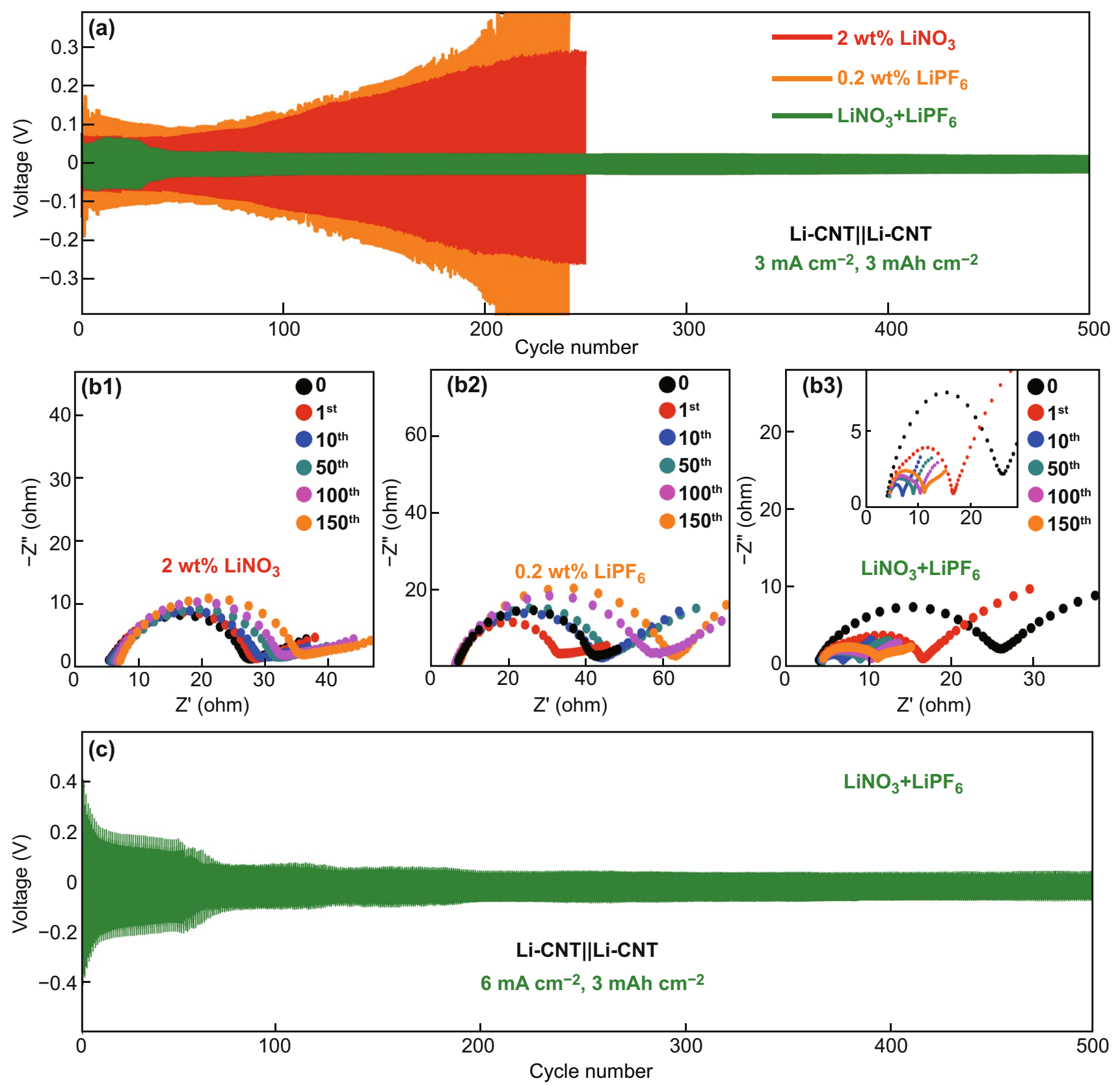

Fig. 2 a Voltage profiles of Li-CNTILi-CNT cells cycling at $3 \mathrm{~mA} \mathrm{~cm}^{-2}, 3 \mathrm{mAh} \mathrm{cm}^{-2}$ in ether-based electrolytes with a single LiNO 3 additive, a single $\mathrm{LiPF}_{6}$ additive, and dual-salt additives of $\mathrm{LiPF}_{6}$ and $\mathrm{LiNO}_{3}$. b1-b3 Nyquist plots of the Li-CNTILi-CNT cells showed at $3 \mathrm{~mA} \mathrm{~cm}^{-2}$,

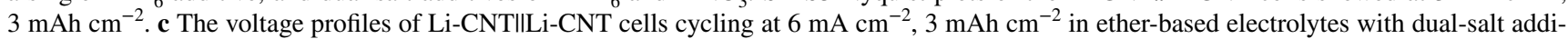
tives of $\mathrm{LiPF}_{6}$ and $\mathrm{LiNO}_{3}$

dramatically improved cycling performance with a significantly stabilized overpotential. As shown in Fig. 2a (green color), the overpotential of the Li-CNTILi-CNT symmetric cell is around $\sim 60 \mathrm{mV}$ for the first 35 cycles and then decrease to $\sim 40 \mathrm{mV}$ that remains for 500 cycles, suggesting that the SEI layer formed during the initial cycles is a good conductor for Li-ions compared to that formed in the electrolyte with a single $\mathrm{LiNO}_{3}$ additive.

The impedance evolution of the Li-CNTILLi-CNT symmetric cells during cycling at a current density of $3 \mathrm{~mA} \mathrm{~cm}^{-2}$ was evaluated by the electrochemical impedance spectroscopy (EIS) measurement. As shown in Fig. 2b1, the 
impedance of the cell that cycled with a single $\mathrm{LiNO}_{3}$ additive increases gradually during cycling, rising from 28 to 36 $\Omega$ after 150 cycles, indicating the formation of ionic insulating SEI layer during cycling. Similar result is observed for that cell with a single $\mathrm{LiPF}_{6}$ additive (Fig. 2b2). While for the Li-CNTIILi-CNT symmetric cell cycled with dual-salt additives of $\mathrm{LiPF}_{6}$ and $\mathrm{LiNO}_{3}$, the impedance keeps decreasing during early cycles from 27 to $6 \Omega$ and then maintains stable at around $10 \Omega$ at 150 cycles (Fig. 2b3), indicating that an ion conductive and robust SEI layer is formed during earlier cycles. This result is in good agreement with the evolution of the overpotential showed in Fig. 2a.

Importantly, when the Li stripping/plating current density was further increased to $6 \mathrm{~mA} \mathrm{~cm}^{-2}$ (Fig. 2c), $8 \mathrm{~mA} \mathrm{~cm}^{-2}$ (Fig. S2a), and $10 \mathrm{~mA} \mathrm{~cm}^{-2}$ (Fig. S2b), the Li-CNT\|Li-CNT symmetric cells cycled with dual-salt additives of $\mathrm{LiPF}_{6}$ and $\mathrm{LiNO}_{3}$ still show very stable cyclability with small overpotentials of
65,118 , and $217 \mathrm{mV}$, respectively, after an SEI formation activation stage at early cycles. These results further suggest that the SEI layer formed in the electrolyte with dual-salt additives of $\mathrm{LiPF}_{6}$ and $\mathrm{LiNO}_{3}$ is well ionic conductive and robust.

It is worth noting that the concentration of the $\mathrm{LiPF}_{6}$ additive was optimized by comparing the overpotential of the LiCNT/ILi-CNT symmetric cells. As shown in Fig. S2c, after 500 cycles under $3 \mathrm{~mA} \mathrm{~cm}{ }^{-2}, 3 \mathrm{mAh} \mathrm{cm}^{-2}$, cells cycled with $0,0.1,0.2,0.3,0.4$, and $0.5 \mathrm{wt} . \%$ of the $\mathrm{LiPF}_{6}$ additive show the average overpotentials of $49,48,42,46,59$, and $79 \mathrm{mV}$, respectively. Therefore, the optimized concentration of the $\mathrm{LiPF}_{6}$ additive was determined to be $0.2 \mathrm{wt} . \%$.

The average cycling CE of the Li-CNT negative electrode in the two different electrolytes was evaluated using a $\mathrm{LiFePO}_{4}$ positive electrode with a practical areal loading of $2.5 \mathrm{mAh} \mathrm{cm} \mathrm{cm}^{-2}$ under a low N/P ratio of 2 . As shown in Fig. 3a, the Li-CNTIILFP cell cycled with a single $\mathrm{LiNO}_{3}$
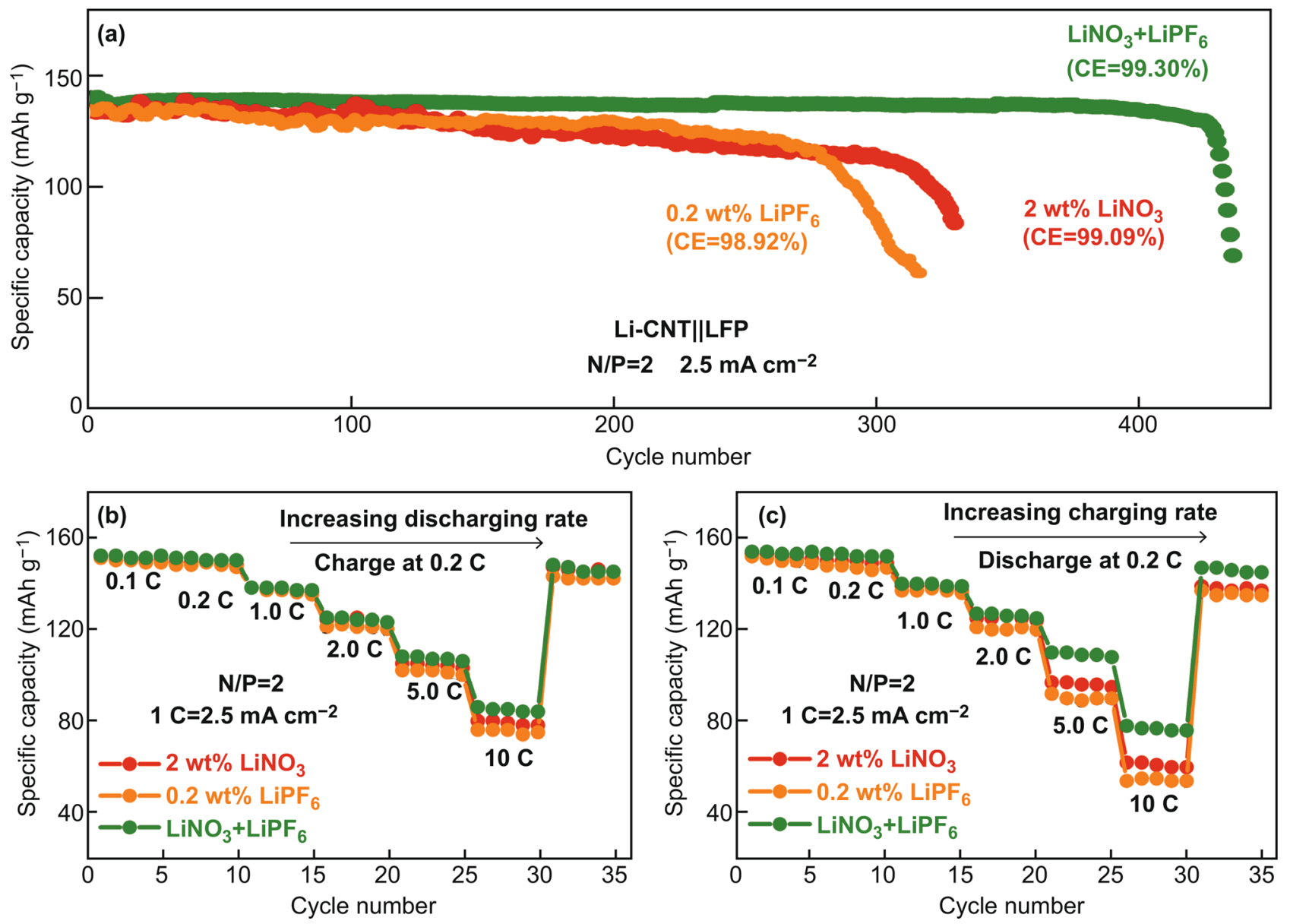

Fig. 3 a Cycle performance of the Li-CNTILFP batteries in ether-based electrolytes with a single $\mathrm{LiNO}_{3}$ additive, a single $\mathrm{LiPF}_{6}$ additive, and dual-salt additives of $\mathrm{LiPF}_{6}$ and $\mathrm{LiNO}_{3}, \mathbf{b}$, $\mathbf{c}$ discharge rate ability and charge rate ability of the Li-CNTIILFP batteries 
additive or a single $\mathrm{LiPF}_{6}$ additive at $1 \mathrm{C}$ bewteen $2.5-4.1 \mathrm{~V}$ maintains stable for around 330 cycles and 270 cycles, respectively. before rapid capacity decay, corresponding to an average cycling CE of $99.09 \%$ and $98.92 \%$, respectively. However, with dual-salt additives of $\mathrm{LiPF}_{6}$ and $\mathrm{LiNO}_{3}$, the cycle life of the Li-CNTIILFP cells can be further extended to 430 cycles, resulting in an average cycling CE of $99.30 \%$, which is the best among reported literatures [37, 41, 42]. The voltage profile evolutions of the Li-CNTILFP cells during cycling in ether-based electrolytes with different additives are showed in Fig. S3. Electrolyte decomposed product can be observed on the Li-CNT electrode in the Li-CNT\|LFP cell after 200 cycles at $1 \mathrm{C}$ in the in ether-based electrolytes with dual-salt additives of $\mathrm{LiPF}_{6}$ and $\mathrm{LiNO}_{3}$ (Fig. S4). However, the thickness of the Li-CNT electrode almost kept the same during cycling.

The Li-CNTIILFP cell cycled with dual-salt additives of $\mathrm{LiPF}_{6}$ and $\mathrm{LiNO}_{3}$ also shows improved rate performance, especially for the charge rate ability. As shown in Fig. 3b, when cells are charged at a constant current of $0.2 \mathrm{C}$ and discharged at various $\mathrm{C}$ rates, the Li-CNTILFP cell with dual-salt additives of $\mathrm{LiPF}_{6}$ and $\mathrm{LiNO}_{3}$ show slightly higher specific discharge capacities at $5 \mathrm{C}$ and $10 \mathrm{C}$ than those of the cell with only $\mathrm{LiNO}_{3}$ additive or $\mathrm{LiPF}_{6}$ additive; when the discharge current density is set at $0.2 \mathrm{C}$ and the charge capacity varies (Fig. 3c), the Li-CNT\|LFP cell with dualsalt additives of $\mathrm{LiPF}_{6}$ and $\mathrm{LiNO}_{3}$ shows even better charge capacities at $5 \mathrm{C}$ and $10 \mathrm{C}$ than that with a single $\mathrm{LiNO}_{3}$ or $\mathrm{LiPF}_{6}$ additive. These results again suggest that the SEI formed under the presence of both $\mathrm{LiPF}_{6}$ and $\mathrm{LiNO}_{3}$ additives has a smaller impedance for conducting the $\mathrm{Li}^{+}$ions.

To probe why the Li-CNT SEI layer formed under the presence of dual-salt additives is more conductive and robust, morphology and chemistry evolution of the LiCNT surface was analyzed by SEM, XPS, and TOF-SIMS. As shown in Fig. 4a, SEM images of the Li-CNT composite before cycling at various magnifications show a clear sponge-like CNT framework. After 50 cycles at a current density of $6 \mathrm{~mA} \mathrm{~cm}^{-2}$, the surface of the Li-CNT electrode cycled with a single $\mathrm{LiNO}_{3}$ additive or a single $\mathrm{LiPF}_{6}$ additive is covered with a thick and uneven deposited layer (Fig. 4b, c). However, the surface of the Li-CNT electrode cycled with dual-salt additives of $\mathrm{LiPF}_{6}$ and $\mathrm{LiNO}_{3}$ is covered with a unique thin surface layer composed of stackedgossamer-like sheets (Fig. 4d), which could protect the lithium metal from the corrosion of the electrolyte and at the same time be a good conductor for Li-ion.

XPS depth profile analysis of the Li-CNT samples reveals very different surface chemistry evolution during cycling in electrolytes with a single $\mathrm{LiNO}_{3}$ additive and with dual-salt additives of $\mathrm{LiPF}_{6}$ and $\mathrm{LiNO}_{3}$. As shown in Fig. 5a1-d1, for the cell after the 1st cycle in the electrolyte with a single $\mathrm{LiNO}_{3}$ additive, the SEI layer on the surface of the $\mathrm{Li}$ CNT electrode mainly composed of $\mathrm{LiN}_{\mathrm{x}} \mathrm{O}_{\mathrm{y}}, \mathrm{Li}_{2} \mathrm{CO}_{3}, \mathrm{Li}_{2} \mathrm{O}$, and $\mathrm{LiF}$, which could be originated from the decomposition of the LiTFSI salt, the ether solvent, and the $\mathrm{LiNO}_{3}$ additive $[12,44]$. This layer is very thin at the 1 st cycle and not uniformly covered on the surface as Li metal can be detected on the surface, and the peak intensity of SEI components decreases with the increasing of the depth (except the $\mathrm{Li}_{2} \mathrm{O}$, which could come from the reaction of the $\mathrm{Li}$ CNT with dissolved $\mathrm{O}_{2} / \mathrm{CO}_{2}$ in the electrolyte and decomposition of $\mathrm{LiNO}_{3}$ [44-46]). The thickness of the SEI layer grows fast with cycles while the components stay almost the same. The intensity of the Li metal detected on the surface of the Li-CNT negative electrode is much weaker at the 10th cycle (Fig. S5a1-d1) and disappears at the 50th cycle (Fig. 5a4-d4) (no signals even after the 30-min Ar sputtering), and the relative intensities of the $\operatorname{LiN}_{\mathrm{x}} \mathrm{O}_{\mathrm{y}}$, $\mathrm{Li}_{2} \mathrm{CO}_{3}, \mathrm{Li}_{2} \mathrm{O}$, and $\mathrm{LiF}$ get stable after 10 cycles and present no obvious variation during the $30-\mathrm{min}$ Ar sputtering. The SEI of the cell after the 1 st cycle in the electrolyte with a single $\mathrm{LiPF}_{6}$ additive is also very thin and mainly composes $\mathrm{LiF}, \mathrm{Li}_{\mathrm{x}} \mathrm{PO}_{\mathrm{y}} \mathrm{F}_{\mathrm{z}}$, poly(DOL), organic carbonate, and $\mathrm{Li}_{2} \mathrm{O}$ (Fig. 5a2-d2). As shown in Fig. 5a5-d5, the relative content of the $\mathrm{Li}_{\mathrm{x}} \mathrm{PO}_{\mathrm{y}} \mathrm{F}_{\mathrm{z}}$ and poly(DOL) increase, while that of the $\mathrm{LiF}$ decrease with cycling. The organic carbonate component seems only present on the top surface layer of the SEI.

The SEI formed on the Li-CNT cycled in the ether electrolyte with dual-salt additives of $\mathrm{LiPF}_{6}$ and $\mathrm{LiNO}_{3}$ exhibits distinct components. As shown in Fig. 5a3-d3, after the 1st cycle, the surface layer of the Li-CNT electrode includes the residual of $\mathrm{LiPF}_{6}$ (at $688 \mathrm{eV}$ in the $\mathrm{F} 1 \mathrm{~s}$ spectrum) [47] and its decomposition product $\mathrm{Li}_{\mathrm{x}} \mathrm{PO}_{\mathrm{y}} \mathrm{F}_{\mathrm{z}}$ [26] (at $686.2 \mathrm{eV}$ on the $\mathrm{Li} 1 \mathrm{~s}$ spectrum), a small amount of $\mathrm{LiF}(684.8 \mathrm{eV}$ on the $\mathrm{F} 1 \mathrm{~s}$ spectrum), and prominent poly(DOL) signal (at $291 \mathrm{eV}$ on the $\mathrm{C} 1 \mathrm{~s}$ and $534.5 \mathrm{eV}$ on the $\mathrm{O} 1 \mathrm{~s}$ spectra). This means that $\mathrm{LiPF}_{6}$ may induce the ring-opening polymerization of the DOL solvent to form polyether products [22]. The SEI layer is quite thin after the 1st cycle, as the intensity 


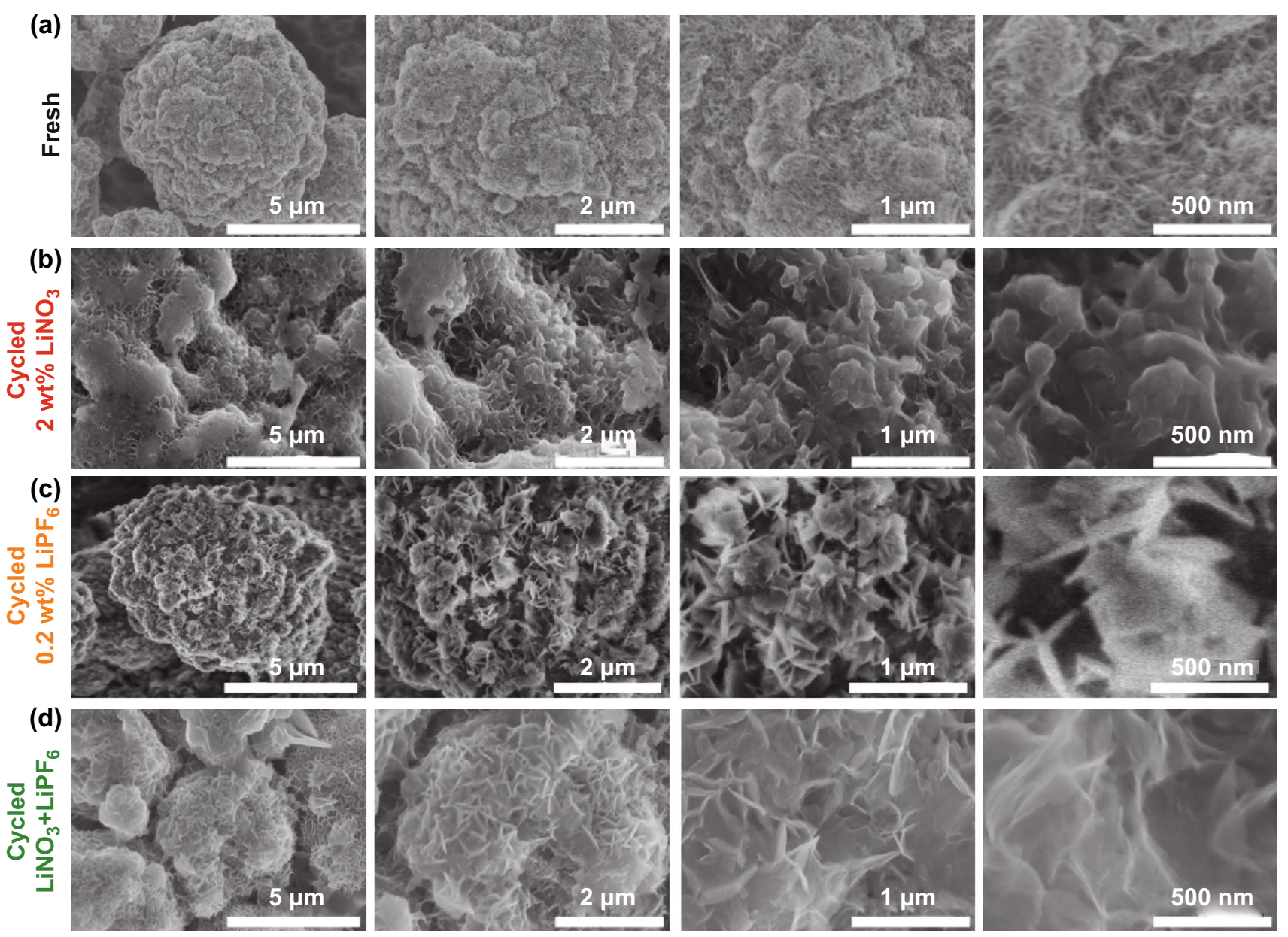

Fig. 4 a-d SEM images of the Li-CNT electrode before (a) and after 50 cycles at a current density of $6 \mathrm{~mA} \mathrm{~cm}{ }^{-2}$ in electrolytes with a single $\mathrm{LiNO}_{3}$ additive (b), $\mathrm{LiPF}_{6}$ additive (c), and dual-salt additives of $\mathrm{LiPF}_{6}$ and $\mathrm{LiNO}_{3}(\mathbf{d})$

of the poly(DOL) decreases gradually during the Ar etching. However, the SEI grows and gets thick enough after the 10th (Fig. S5a2-d2) and 50th cycle (Fig. 5a6-d6), where no intensity variation can be observed for the SEI component during the 30-min Ar etching. The $\mathrm{LiF} / \mathrm{Li}_{\mathrm{x}} \mathrm{PO}_{\mathrm{y}} \mathrm{F}_{\mathrm{z}}$ components formed with the help of the $\mathrm{LiPF}_{6}$ additive could guarantee the mechanical strength and ionic conductivity of the SEI [26, 48, 49], while the organic polyether has better volume tolerance ability than inorganic salts components such as lithium alkyl and lithium carbonate that formed under a single $\mathrm{LiNO}_{3}$ additive $[24,50]$. This could be the reason that a trace amount of $\mathrm{LiPF}_{6}$ additive can significantly improve the cycle performance of the Li-CNT negative electrode.

The different SEI chemistry of the Li-CNT electrodes after 50 cycles in ether-based electrolytes with a single $\mathrm{LiNO}_{3}$ additive and dual-salt additives of $\mathrm{LiPF}_{6}$ and $\mathrm{LiNO}_{3}$ has also been observed at the nano-scale by TOF-SIMS, which is a highly surface-sensitive technique with ultrahigh chemical selectivity. As shown in Fig. $6 \mathrm{a} 2$ and b2, a distinguishable $\mathrm{PO}^{-}$and $\mathrm{PO}_{2}{ }^{-}$signal appears in the Li-CNT electrode cycled with dual-salt additives of $\mathrm{LiPF}_{6}$ and $\mathrm{LiNO}_{3}$, which confirms the observation of the $\mathrm{Li}_{\mathrm{X}} \mathrm{PO}_{\mathrm{y}} \mathrm{F}_{\mathrm{z}}$ component in the XPS spectra. The content of $\mathrm{C}_{2} \mathrm{HO}^{-}$(representing organic SEI components that come from the solvent decomposition) on the Li-CNT electrode cycled with a single $\mathrm{LiNO}_{3}$ additive was relatively higher than that cycled with dual-salt additives of $\mathrm{LiPF}_{6}$ and $\mathrm{LiNO}_{3}$ (Fig. 6a1 and b1), indicating that the addition of $\mathrm{LiPF}_{6}$ additives can inhibit the decomposition of the organic solvents. Last but not the least, much higher $\mathrm{LiO}^{-}$and $\mathrm{LiF}_{2}{ }^{-}$signals can also be observed on the Li-CNT electrode cycled with a single $\mathrm{LiNO}_{3}$ additive, revealing the severe decomposition of the ether solvent and the LiTFSI salt. 
$1^{\text {st }}$ cycle
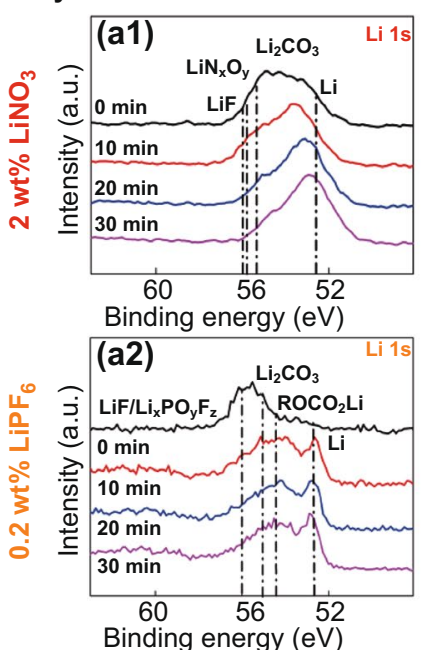

(a3) $\quad \operatorname{LiN}_{x} \mathrm{O}_{y}$

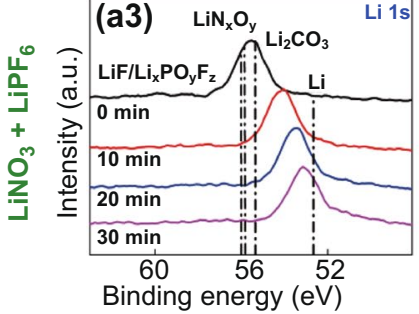

$50^{\text {th }}$ cycle

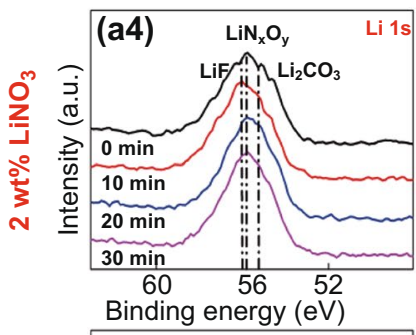

(a5)
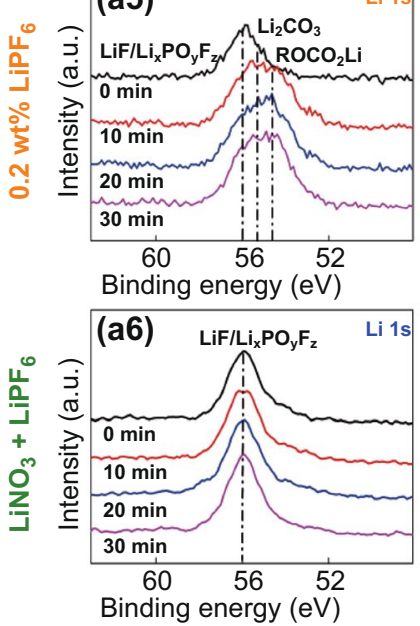

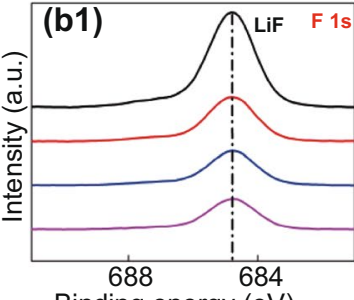

Binding energy (eV)
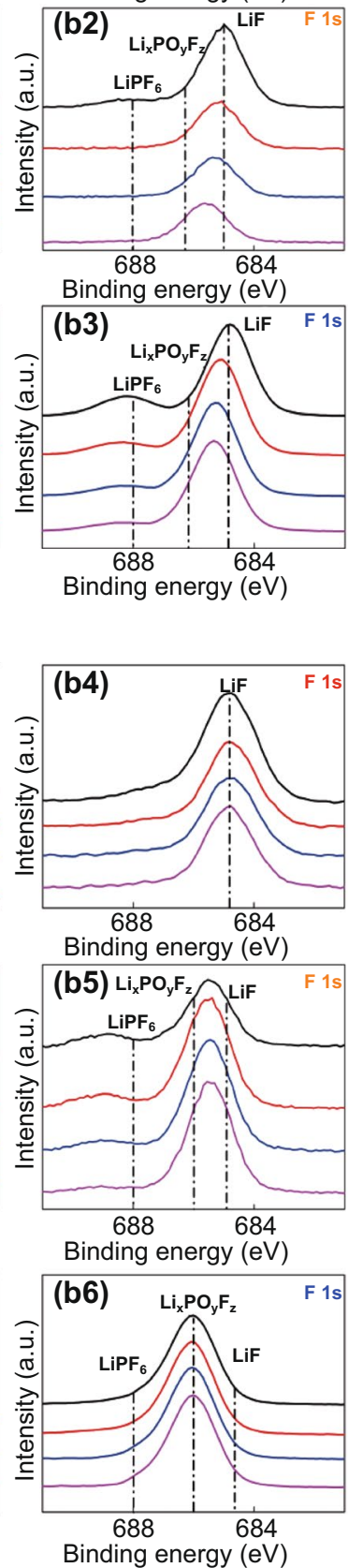
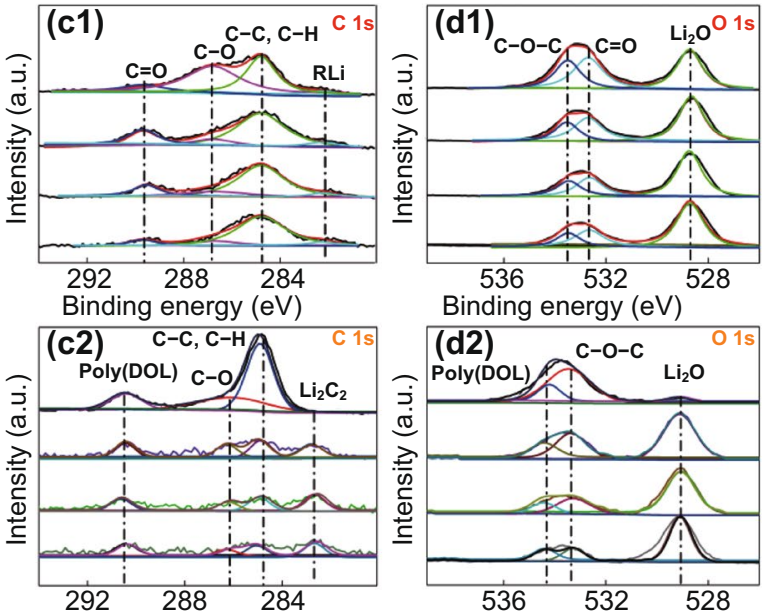

Binding energy (eV)
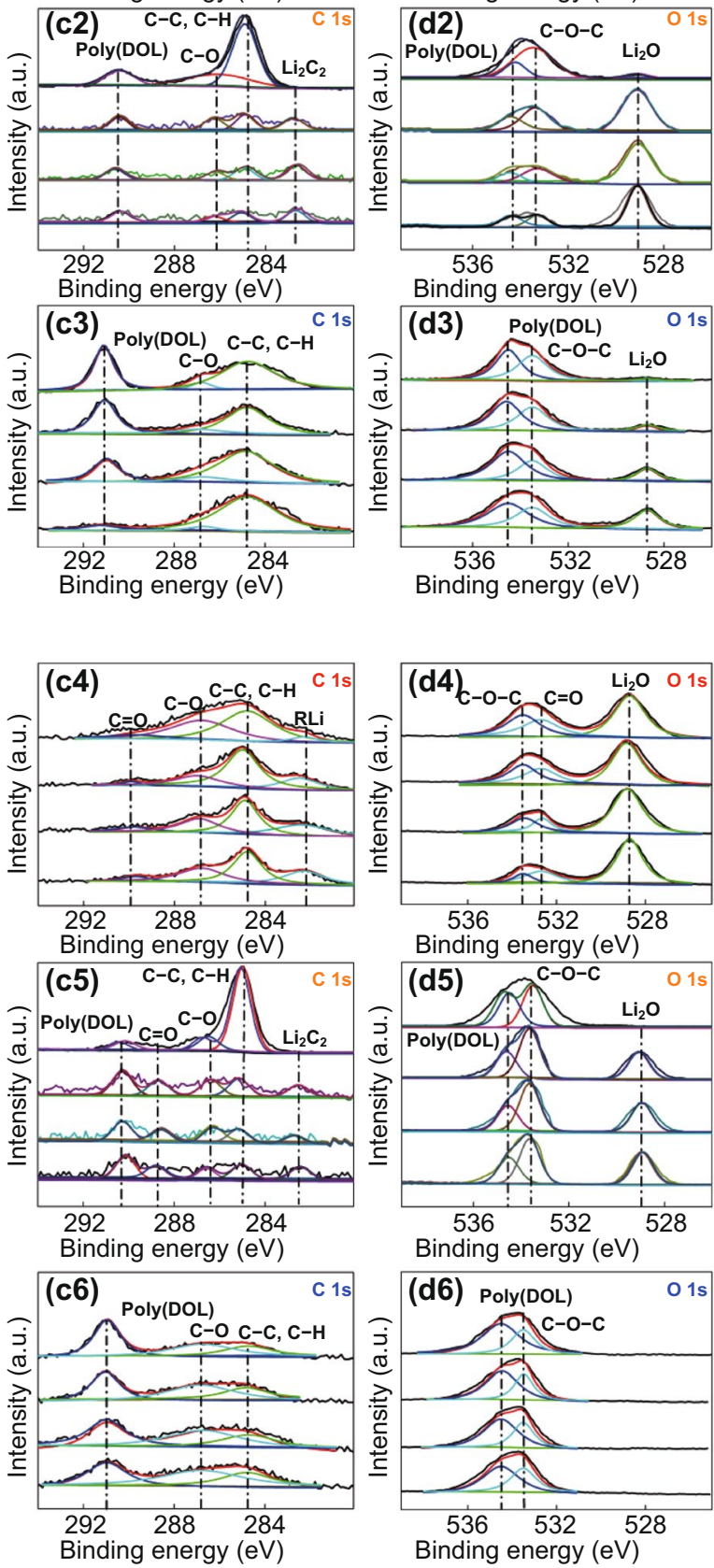

Fig. 5 a-d Li 1s, F 1s, C 1s, and O 1s XPS depth profiles (etching time: 0 min, 10 min, 20 min, and 30 min) of the Li-CNT electrodes after different cycles in electrolytes with a single $\mathrm{LiNO}_{3}$ additive $(\mathbf{a 1}-\mathbf{d 1}, \mathbf{a} \mathbf{-}-\mathbf{d 4}), \mathrm{LiPF}_{6}$ additive $(\mathbf{a} 2-\mathbf{d} 2, \mathbf{a 5}-\mathbf{d 5})$, and dual-salt additives of $\mathrm{LiPF}_{6}$ and $\mathrm{LiNO}_{3}(\mathbf{a 3}-\mathbf{d 3}, \mathbf{a 6}-\mathbf{d 6})$ 

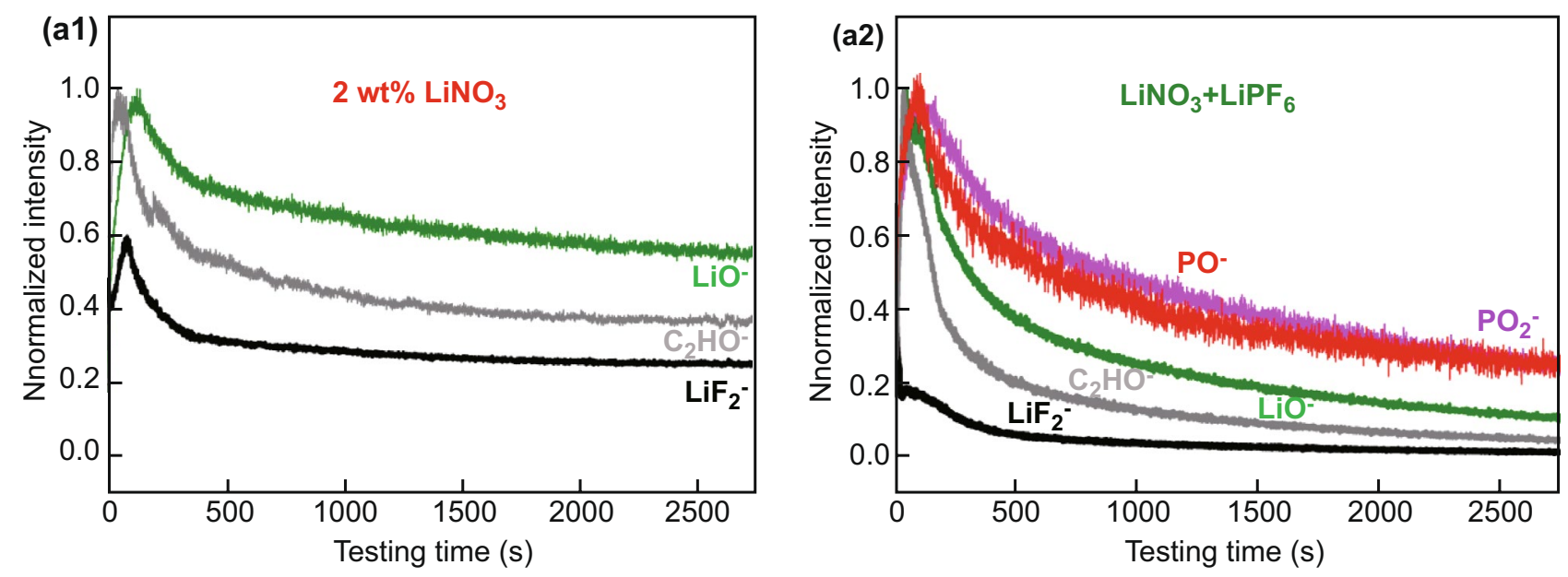

(b1)
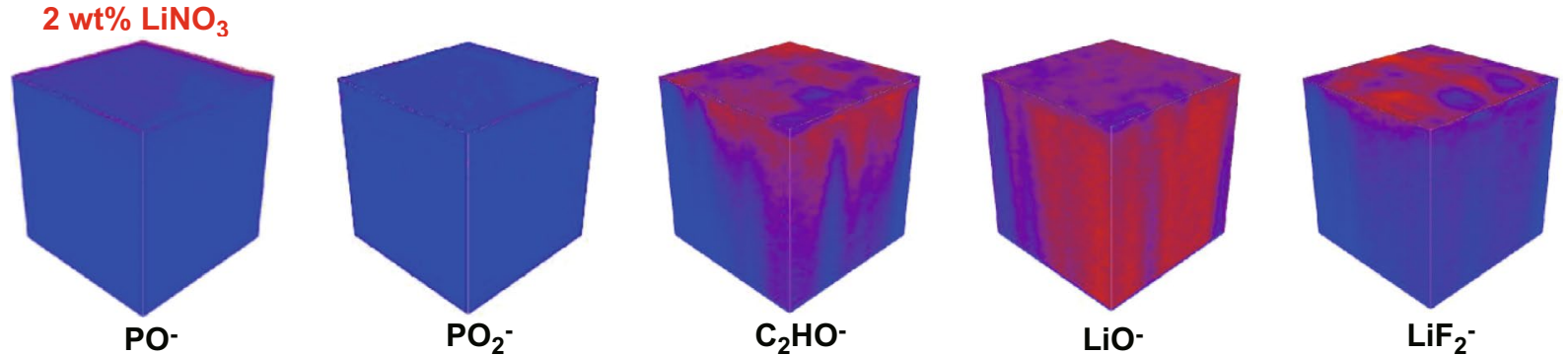

(b2)
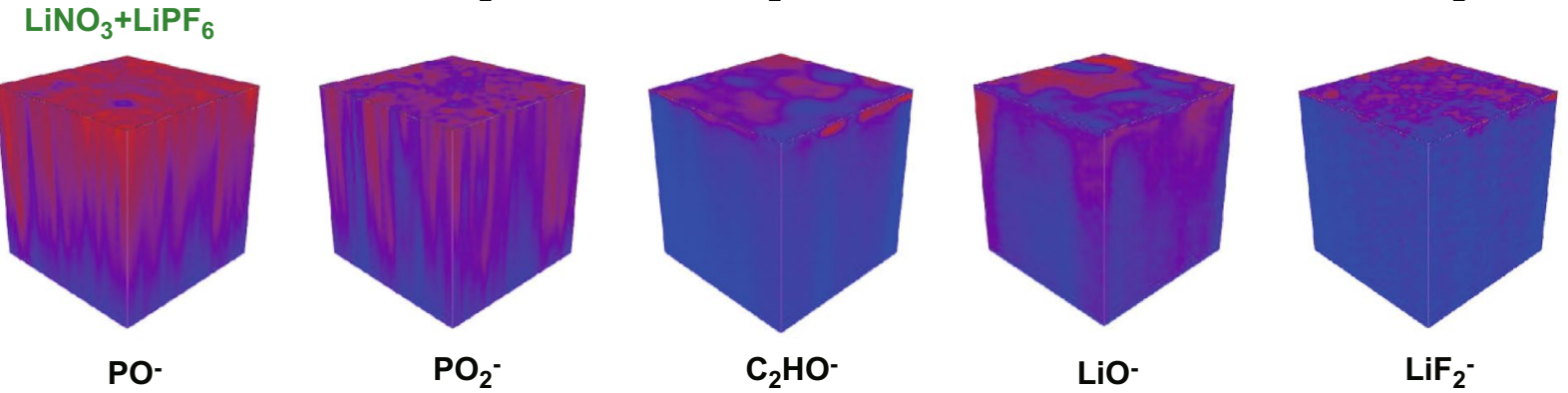

Fig. 6 a, b TOF-SIMS depth profiles and distributions of $\mathrm{PO}^{-}, \mathrm{PO}_{2}^{-}, \mathrm{C}_{2} \mathrm{HO}^{-}, \mathrm{LiO}^{-}$, and $\mathrm{LiF}_{2}^{-}$species on the surface of the $\mathrm{Li}-\mathrm{CNT}$ electrodes after 50 cycles in electrolytes with a single $\mathrm{LiNO}_{3}$ additive $(\mathbf{a 1}, \mathbf{b 1})$ and dual-salt additives of $\mathrm{LiPF}_{6}$ and $\mathrm{LiNO}_{3}(\mathbf{a} 2, \mathbf{b 2})$

\section{Conclusions}

We demonstrated that the combined use of $\mathrm{LiPF}_{6}$ and $\mathrm{LiNO}_{3}$ additives in an ether-based electrolyte can significantly improve the cycling performance and rate capability of the Li-CNT negative electrode. The $\mathrm{LiNO}_{3}$ additive can generate inorganic products like $\mathrm{LiN}_{\mathrm{x}} \mathrm{O}_{\mathrm{y}}$, which have good mechanical strength, while the $\mathrm{LiPF}_{6}$ additive can help to induce the ring-opening polymerization of the DOL solvent to form polyether with good volumetric variation tolerance. These products together form an ionic conductive and robust SEI layer on the surface of the Li-CNT negative electrode. As a result, the Li-CNTIILFP cells with limited lithium excess
$(\mathrm{N} / \mathrm{P}=2)$ has obtained an average cycling $\mathrm{CE}$ as high as $99.30 \%$ under a current density of $2.5 \mathrm{~mA} \cdot \mathrm{cm}^{-2}$.

Acknowledgements This research was financially supported by the National Natural Science Foundation of China (Grant nos. 21625304 and 21733012), and the Ministry of Science and Technology (Grant No. 2016YFA0200703).

Open Access This article is licensed under a Creative Commons Attribution 4.0 International License, which permits use, sharing, adaptation, distribution and reproduction in any medium or format, as long as you give appropriate credit to the original author(s) and the source, provide a link to the Creative Commons licence, and indicate if changes were made. The images or other third party material in this article are included in the article's Creative Commons licence, unless indicated otherwise in a credit line to the 
material. If material is not included in the article's Creative Commons licence and your intended use is not permitted by statutory regulation or exceeds the permitted use, you will need to obtain permission directly from the copyright holder. To view a copy of this licence, visit http://creativecommons.org/licenses/by/4.0/.

Supplementary Information The online version contains supplementary material available at https://doi.org/10.1007/ s40820-021-00633-3.

\section{References}

1. X.B. Cheng, R. Zhang, C.Z. Zhao, Q. Zhang, Toward safe lithium metal anode in rechargeable batteries: a review. Chem. Rev. 117, 10403-10473 (2017). https://doi.org/10.1021/acs. chemrev.7b00115

2. D.C. Lin, Y.Y. Liu, Y. Cui, Reviving the lithium metal anode for high-energy batteries. Nat. Nanotechnol. 12, 194-206 (2017). https://doi.org/10.1038/NNANO.2017.16

3. A. Zhamu, G.R. Chen, C.G. Liu, D. Neff, Q. Fang et al., Reviving rechargeable lithium metal batteries: enabling nextgeneration high-energy and high-power cells. Energy Environ. Sci. 5, 5701-5707 (2012). https://doi.org/10.1039/C2EE0 2911A

4. C.P. Yang, K. Fu, Y. Zhang, E. Hitz, L.B. Hu, Protected lithium-metal anodes in batteries: from liquid to solid. Adv. Mater. 29, 1701169 (2017). https://doi.org/10.1002/adma. 201701169

5. W. Xu, J.L. Wang, F. Ding, X.L. Chen, E. Nasybutin et al., Lithium metal anodes for rechargeable batteries. Energy Environ. Sci. 7, 513-537 (2014). https://doi.org/10.1039/C3EE4 $0795 \mathrm{~K}$

6. M.R. Palacin, A. de Guibert, Why do batteries fail? Science 351, 1253292 (2016). https://doi.org/10.1126/science.12532 92

7. M. Armand, J.M. Tarascon, Building better batteries. Nature 451, 652-657 (2008). https://doi.org/10.1038/451652a

8. R. Zhang, X.R. Chen, X. Chen, X.B. Cheng, X.Q. Zhang et al., Lithiophilic sites in doped graphene guide uniform lithium nucleation for dendrite-free lithium metal anodes. Angew. Chem. Int. Ed. 56, 7764-7768 (2017). https://doi.org/10.1002/ anie.201702099

9. J.M. Tarascon, M. Armand, Issues and challenges facing rechargeable lithium batteries. Nature 414, 359-367 (2001). https://doi.org/10.1038/35104644

10. X.L. Ji, K.T. Lee, L.F. Nazar, A highly ordered nanostructured carbon-sulphur cathode for lithium-sulphur batteries. Nat. Mater. 8, 500-506 (2009). https://doi.org/10.1038/NMAT2460

11. R.G. Cao, W. Xu, D.P. Lv, J. Xiao, J.G. Zhang, Anodes for rechargeable lithium-sulfur batteries. Adv. Energy Mater. 5, 1402273 (2015). https://doi.org/10.1002/aenm.201402273

12. X.B. Cheng, R. Zhang, C.Z. Zhao, F. Wei, J.G. Zhang et al., A review of solid electrolyte interphases on lithium metal anode. Adv. Sci. 3, 1500213 (2016). https://doi.org/10.1002/ advs.201500213

13. Y. Gao, Y.M. Zhao, Y.G.C. Li, Q.Q. Huang, T.E. Mallouk et al., Interfacial chemistry regulation via a skin-grafting strategy enables high-performance lithium-metal batteries. J. Am. Chem. Soc. 139, 15288-15291 (2017). https://doi.org/10. 1021/jacs.7b06437

14. K. Yan, Z.D. Lu, H.W. Lee, F. Xiong, P.C. Hsu et al., Selective deposition and stable encapsulation of lithium through heterogeneous seeded growth. Nat. Energy 1, 16010 (2016). https://doi.org/10.1038/NENERGY.2016.10

15. R. Zhang, X. Chen, X. Shen, X.Q. Zhang, X.R. Chen et al., Coralloid carbon fiber-based composite lithium anode for robust lithium metal batteries. Joule 2, 764-777 (2018). https://doi.org/10.1016/j.joule.2018.02.001

16. L. Liu, Y.X. Yin, J.Y. Li, S.H. Wang, Y.G. Guo et al., Uniform lithium nucleation/growth induced by lightweight nitrogendoped graphitic carbon foams for high-performance lithium metal anodes. Adv. Mater. 30, 1706216 (2018). https://doi. org/10.1002/adma.201706216

17. T. Kang, J.H. Zhao, F. Guo, L. Zheng, Y.Y. Mao et al., Dendrite-free lithium anodes enabled by a commonly used copper antirusting agent. ACS Appl. Mater. Interfaces 12, 8168-8175 (2020). https://doi.org/10.1021/acsami.9b19655

18. Z. Liang, D.C. Lin, J. Zhao, Z.D. Lu, Y.Y. Liu et al., Composite lithium metal anode by melt infusion of lithium into a $3 \mathrm{~d}$ conducting scaffold with lithiophilic coating. Proc. Natl. Acad. Sci. U.S.A. 113, 2862-2867 (2016). https://doi.org/10.1073/ pnas. 1518188113

19. W.J. Tang, S. Tang, X.Z. Guan, X.Y. Zhang, Q. Xiang et al., High-performance solid polymer electrolytes filled with vertically aligned 2D materials. Adv. Funct. Mater. 29, 1900648 (2019). https://doi.org/10.1002/adfm.201900648

20. S.M. Xu, D.W. McOwen, C.W. Wang, L. Zhang, W. Luo et al., Three-dimensional, solid-state mixed electron-ion conductive framework for lithium metal anode. Nano Lett. 18, 3926-3933 (2018). https://doi.org/10.1021/acs.nanolett.8b01295

21. C.Y. Zhang, S. Liu, G.J. Li, C.J. Zhang, X.J. Liu et al., Incorporating ionic paths into $3 \mathrm{~d}$ conducting scaffolds for high volumetric and areal capacity, high rate lithium-metal anodes. Adv. Mater. 30, 1801328 (2018). https://doi.org/10.1002/ adma.201801328

22. F.Q. Liu, W.P. Wang, Y.X. Yin, S.F. Zhang, J.L. Shi et al., Upgrading traditional liquid electrolyte via in situ gelation for future lithium metal batteries. Sci. Adv. 4, eaat5383 (2018). https://doi.org/10.1126/sciadv.aat5383

23. H.F. Fei, Y.P. Liu, C.L. Wei, Y.C. Zhang, J.K. Feng et al., Poly(propylene carbonate)-based polymer electrolyte with an organic cathode for stable all-solid-state sodium batteries. Acta Phys.-Chim. Sin. 36, 1905015 (2020). https://doi.org/10. 3866/PKU.WHXB201905015

24. J.M. Zheng, M.H. Engelhard, D.H. Mei, S.H. Jiao, B.J. Polzin et al., Electrolyte additive enabled fast charging and stable cycling lithium metal batteries. Nat. Energy 2, 17012 (2017). https://doi.org/10.1038/nenergy.2017.12 
25. Q. Ran, T. Sun, C. Han, H. Zhang, J. Yan et al., Natural polyphenol tannic acid as an efficient electrolyte additive for high performance lithium metal anode. Acta Phys. Chim. Sin. (2020). https://doi.org/10.3866/pku.Whxb201912068

26. W.G. Zhao, J.M. Zheng, L.F. Zou, H.P. Jia, B. Liu et al., High voltage operation of ni-rich nmc cathodes enabled by stable electrode/electrolyte interphases. Adv. Energy Mater. 8, 1800297 (2018). https://doi.org/10.1002/aenm.201800297

27. Z.J. Cheng, Y.Y. Mao, Q.Y. Dong, F. Jin, Y.B. Shen et al., Fluoroethylene carbonate as an additive for sodium-ion batteries: effect on the sodium cathode. Acta Phys. Chim. Sin. 35, 868-875 (2019). https://doi.org/10.3866/PKU.WHXB201811033

28. G.H. Chen, Y. Bai, Y.S. Gao, F. Wu, C. Wu, Chalcogenide electrolytes for all-solid-state sodium ion batteries. Acta Phys. Chim. Sin. 36, 1905009 (2020). https://doi.org/10.3866/PKU. WHXB201905009

29. X.Q. Zhang, X.B. Cheng, X. Chen, C. Yan, Q. Zhang, Fluoroethylene carbonate additives to render uniform li deposits in lithium metal batteries. Adv. Funct. Mater. 27, 1605989 (2017). https://doi.org/10.1002/adfm.201605989

30. J. Meng, F. Chu, J. Hu, C. Li, Liquid polydimethylsiloxane grafting to enable dendrite-free li plating for highly reversible li-metal batteries. Adv. Funct. Mater. 29, 1902220 (2019). https://doi.org/10.1002/adfm.201902220

31. Z. Ju, J. Nai, Y. Wang, T. Liu, J. Zheng et al., Biomacromolecules enabled dendrite-free lithium metal battery and its origin revealed by cryo-electron microscopy. Nat. Commun. 11, 488 (2020). https://doi.org/10.1038/s41467-020-14358-1

32. B.Q. Li, X.R. Chen, X. Chen, C.X. Zhao, R. Zhang et al., Favorable lithium nucleation on lithiophilic framework porphyrin for dendrite-free lithium metal anodes. Research 2019, 4608940 (2019). https://doi.org/10.34133/2019/4608940

33. Y. Chen, M. Yue, C. Liu, H. Zhang, Y. Yu et al., Long cycle life lithium metal batteries enabled with upright lithium anode. Adv. Funct. Mater. 29, 1806752 (2019). https://doi.org/10. 1002/adfm.201806752

34. X.-Y. Hu, P. Xu, S. Deng, J. Lei, X. Lin et al., Inducing ordered li deposition on a pani-decorated cu mesh for an advanced li anode. J. Mater. Chem. A 8, 17056-17064 (2020). https://doi. org/10.1039/d0ta03929b

35. Q. Wang, C. Yang, J. Yang, K. Wu, C. Hu et al., Dendrite-free lithium deposition via a superfilling mechanism for high-performance li-metal batteries. Adv. Mater. 31, e1903248 (2019). https://doi.org/10.1002/adma.201903248

36. Y. Liu, L. Zheng, W. Gu, Y. Shen, L. Chen, Surface passivation of lithium metal $<\mathrm{i}>$ via in $\mathrm{situ}</ \mathrm{i}>$ polymerization. Acta Phys. Chim. Sin. (2020). https://doi.org/10.3866/pku.Whxb2 02004058

37. Y.L. Wang, Y.B. Shen, Z.L. Du, X.F. Zhang, K. Wang et al., A lithium-carbon nanotube composite for stable lithium anodes. J. Mater. Chem. A 5, 23434-23439 (2017). https://doi.org/10. 1039/C7TA08531A

38. F. Guo, Y.L. Wang, T. Kang, C.H. Liu, Y.B. Shen et al., A lidual carbon composite as stable anode material for li batteries.
Energy Storage Mater. 15, 116-123 (2018). https://doi.org/10. 1016/j.ensm.2018.03.018

39. F. Guo, P. Chen, T. Kang, Y.L. Wang, C.H. Liu et al., Siliconloaded lithium-carbon composite microspheres as lithium secondary battery anodes. Acta Phys. Chim. Sin. 35, 1365-1371 (2019). https://doi.org/10.3866/Pku.Whxb201903008

40. F. Guo, T. Kang, Z.J. Liu, B. Tong, L.M. Guo et al., Advanced lithium metal-carbon nanotube composite anode for high-performance lithium-oxygen batteries. Nano Lett. 19, 6377-6384 (2019). https://doi.org/10.1021/acs.nanolett.9b02560

41. T. Kang, Y.L. Wang, F. Guo, C.B. Liu, J.H. Zhao et al., Selfassembled monolayer enables slurry-coating of li anode. ACS Cen. Sci. 5, 468-476 (2019). https://doi.org/10.1021/acsce ntsci.8b00845

42. L. Zheng, F. Guo, T. Kang, J. Yang, Y. Liu et al., Highly stable lithium anode enabled by self-assembled monolayer of dihexadecanoalkyl phosphate. Nano Res. 13, 1324-1331 (2019). https://doi.org/10.1007/s12274-019-2565-7

43. W. Gu, Q.Y. Dong, L. Zheng, Y. Liu, Y.Y. Mao et al., Ambient air stable ni-rich layered oxides enabled by hydrophobic self-assembled monolayer. ACS Appl. Mater. Interfaces 12, 1937-1943 (2020). https://doi.org/10.1021/acsami.9b20030

44. S.S. Zhang, A new finding on the role of lino3 in lithiumsulfur battery. J. Power Sources 322, 99-105 (2016). https:// doi.org/10.1016/j.jpowsour.2016.05.009

45. J. Guo, Z.Y. Wen, M.F. Wu, J. Jin, Y. Liu, Vinylene carbonatelino3: a hybrid additive in carbonic ester electrolytes for sei modification on li metal anode. Electrochem. Commun. 51, 59-63 (2015). https://doi.org/10.1016/j.elecom.2014.12.008

46. W.D. Zhang, Q. Wu, J.X. Huang, L. Fan, Z.Y. Shen et al., Colossal granular lithium deposits enabled by the grain-coarsening effect for high-efficiency lithium metal full batteries. Adv. Mater. 32, 2001740 (2020). https://doi.org/10.1002/adma. 202001740

47. P. Verma, P. Maire, P. Novak, A review of the features and analyses of the solid electrolyte interphase in li-ion batteries. Electrochim. Acta 55, 6332-6341 (2010). https://doi.org/10. 1016/j.electacta.2010.05.072

48. W. Huang, H. Wang, D.T. Boyle, Y.Z. Li, Y. Cui, Resolving nanoscopic and mesoscopic heterogeneity of fluorinated species in battery solid-electrolyte interphases by cryogenic electron microscopy. ACS Energy Lett. 5, 1128-1135 (2020). https://doi.org/10.1021/acsenergylett.0c00194

49. Y. Gao, T. Rojas, K. Wang, S. Liu, D.W. Wang et al., Lowtemperature and high-rate-charging lithium metal batteries enabled by an electrochemically active monolayer-regulated interface. Nat. Energy 5, 534-542 (2020). https://doi.org/10. 1038/s41560-020-0640-7

50. M.F. Chu, D.Q. Meng, Y.R. Li, M. Wang, S. Xiao et al., The solid reaction of lithium hydride and lithium hydroxide in lithium hydride pellet under normal condition and the application of $\mathrm{CO}_{2}$ for long-time storage. Appl. Surf. Sci. 447, 673-676 (2018). https://doi.org/10.1016/j.apsusc.2018.04.024 